\title{
XPS Investigation of a CdS-Based Photoresistor under Working Conditions: Operando-XPS
}

\author{
Hikmet Sezen, ${ }^{\dagger}$ Angus A. Rockett, ${ }^{\dagger}$ and Sefik Suzer, ${ }^{*}$ \\ ${ }^{\dagger}$ Department of Chemistry, Bilkent University, 06800 Ankara, Turkey \\ ${ }^{\ddagger}$ Department of Materials Science and Engineering, University of Illinois, Urbana, Illinois 61801, United States
}

Supporting Information

ABSTRACT: A noncontact chemical and electrical measurement X-ray photoelectron spectroscopy (XPS) technique is performed to investigate a CdS-based photoresistor during its operation. The main objective of the technique is to trace chemical- and location-specified surface potential variations as shifts of the XPS Cd $3 \mathrm{~d}_{5 / 2}$ peak position without and under photoillumination with four different lasers. The system is also modeled to extract electrical information. By analyzing the measured potential variations with this model, locationdependent resistance values are represented (i) two dimensionally for line scans and (ii) three dimensionally for areal

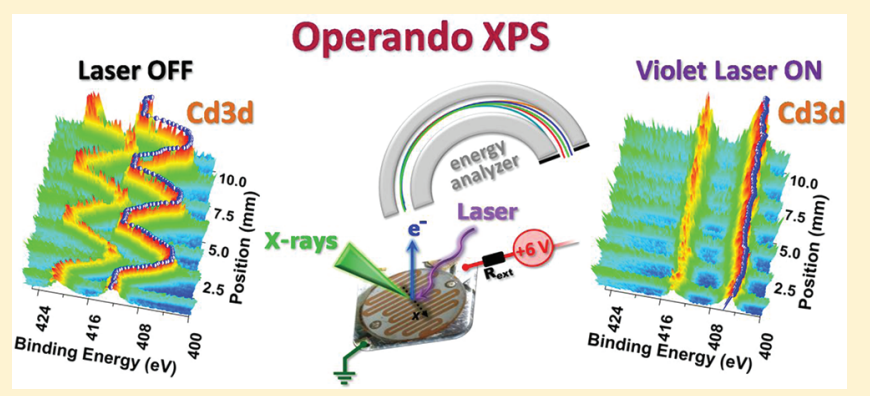
measurements. In both cases, one of the dimensions is the binding energy. The main advantage of the technique is its ability to assess an element-specific surface electrical potential of a device under operation based on the energy deviation of core level peaks in surface domains. Detection of the variations in electrical potentials and especially their responses to the energy of the illuminating source in operando, is also shown to be capable of detecting, locating, and identifying the chemical nature of structural and other types of defects.

$\mathrm{M}$ any powerful analytical techniques are being increasingly utilized to probe the chemical, physical, or electrical parameters of materials and devices under realistic operating conditions, known as operando techniques. ${ }^{1}$ Most of these are photon-based, such as infrared, Raman, sum-frequency generation, X-ray emission and absorption spectroscopies, and their derivatives, such as extended X-ray absorption fine structure (EXAFS), X-ray absorption near-edge structure (XANES), etc. ${ }^{2-17}$ Since particle-based systems such as Auger electron spectroscopy (AES) or X-ray photoelectron spectroscopy (XPS) require a high vacuum environment, their utilization has not been extensive. On the other hand, the conventional scanning probe techniques, such as atomic force microscopy (AFM), scanning tunneling microscopy (STM), Kelvin probe, etc., provide excellent nanometer spatial resolution for electrical characterizations, but do not have any chemical specificity. This is an important drawback. In addition to the powerful elemental and chemical specificity of the AES and XPS, their ability to reflect the electrical potential of the medium surrounding the probed atom, created intentionally or not, ${ }^{18-20}$ renders them even more powerful for understanding device performances under operational conditions. Electrical potential variations across a working device were first reported using AES three decades ago, but the technique has not been pursued, because of its limited chemical specificity. ${ }^{21-25}$ There have also been few attempts to probe potential variations across a working $p-n$ junction device using PEEM (photoemission electron microscopy), which is a variant of electron spectroscopy, which also has limited chemical specificity. ${ }^{26}$

With the recent critical advances in ambient-pressure XPS (APXPS), ${ }^{27,28}$ new and exciting applications toward the investigation of devices under more-realistic operational conditions are also surfacing. ${ }^{29,30}$ In parallel with these developments, recent advances in commercial XPS instrumentation such as microfocusing and parallel detection systems have also provided new possibilities to record XPS data with higher resolution in either line-scan or areal mapping modes with good statistics and in reasonable times. ${ }^{31}$ Here, we present an XPS investigation of a CdS-based photoresistor, taking advantage of these instrumentation capabilities, under working conditions for the device. The electrical potential across the photoresistor is mapped by recording the $\mathrm{Cd} 3 \mathrm{~d}$ peaks with and without illumination with different lasers. A simple electrical model is used to extract electrical parameters in this noncontact fashion. Furthermore, morphologic defects affecting the performance of the device, and their response to different light sources were also determined in a chemically specific fashion. We show that our method is an operando XPS technique, although our measurements are carried out in a vacuum environment.

Received: January 21, 2012

Accepted: February 27, 2012

Published: February 27, 2012 


\section{EXPERIMENTAL SECTION}

A commercially available (OEM) photoresistor or lightdependent resistor (LDR) was studied after removing the protective polymer coating with organic solvents. A Thermo Fisher K-Alpha electron spectrometer with monochromatic Al $\mathrm{K} \alpha \mathrm{X}$-rays was used for the XPS analysis. The instrument was slightly modified to allow imposition of an external voltage across the sample during data acquisition. ${ }^{32,33}$ The spectrometer is equipped with a low-energy flood-gun facility for charge neutralization, utilizing only electrons or both electrons and $\mathrm{Ar}^{+}$ ions. For some of the measurements, the sample surfaces were gently cleaned by sputtering with a low-energy $(200 \mathrm{eV}) \mathrm{Ar}^{+}$ion gun. The survey spectra were recorded with an X-ray beam size of $400 \mu \mathrm{m}$, but for the line scan and areal mapping, a smaller, $30-\mu \mathrm{m}$-diameter X-ray spot size was used with steps of $60 \mu \mathrm{m}$ between data points. For photoillumination, any of four different lasers were used, with an average rated power of $\sim 50$ $\mathrm{mW}$ and emission wavelengths of 405, 532, 635, and $980 \mathrm{~nm}$.

\section{RESULTS AND DISCUSSION}

The LDR has an interdigitated design consisting of conductive electrodes separated by a serpentine photoresponsive region. These are chemically and electronically different, as can be seen from the inset of Figure 1. A survey XPS spectrum confirmed

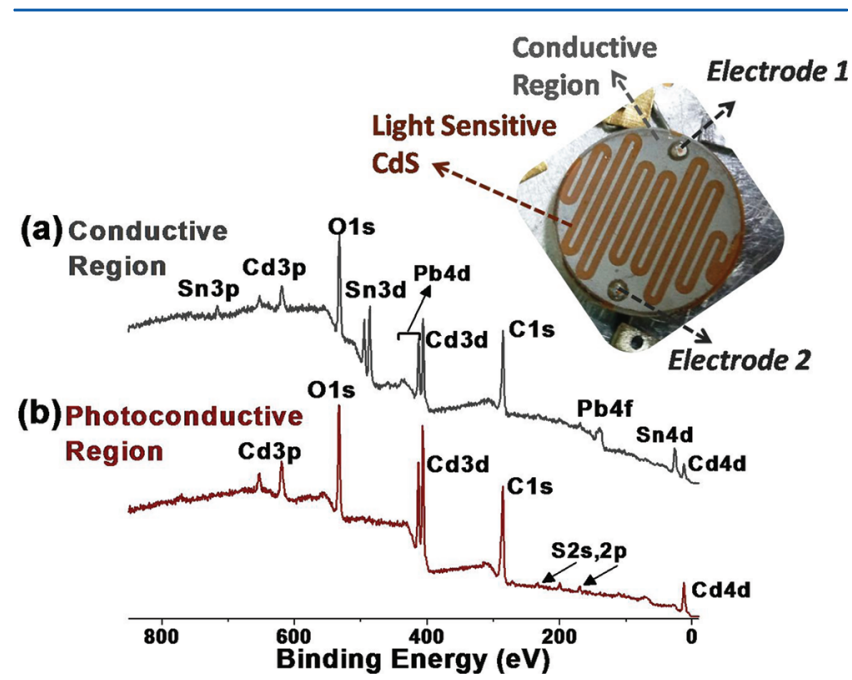

Figure 1. XPS survey spectra of (a) the conductive (gray) and (b) the photoresponsive (brown) regions of a CdS-based photoresistor. The inset shows an optical picture of the device and the electrical connections.

that the brownish zigzag region is almost pure CdS photoconductive material, which is supported by a ceramic substrate. The two gray electrode regions consist of heavily $\mathrm{Sn}$ - and $\mathrm{Pb}$ doped CdS, and are electrically conductive. ${ }^{34}$ Because of the relatively small photoelectron yield for the $S 2 s$ and 2 p peaks, the sulfur content of the regions is barely detectable, based on the survey spectra before $\mathrm{Ar}^{+}$-ion etching, but becomes more visible afterward. Both the conductive and photoconductive region spectra include a certain amount of carbon and oxygen signal, which are reduced after etching.

In order to observe a laterally resolved potential distribution across the LDR, the measurement was performed under an external bias during XPS data collection. This also reproduces realistic operating conditions. One of the electrodes was connected to a $+6 \mathrm{~V}$ dc power supply through an external resistor of $22 \mathrm{k} \Omega$, and the other was grounded as shown in Figure 2. The external (ballast) resistor was introduced to

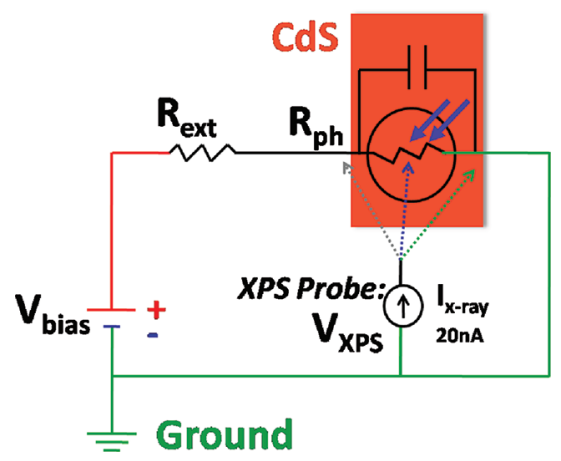

Figure 2. Electric circuit model of the experimental setup to simulate the LDR (location-dependent resistance) behavior of a CdS semiconductor under realistic conditions.

control the flow of the current and to avoid saturation of the photoconductive region by injection of excess charges under light exposure. Note that all of the applied potential is expected to develop across the brown photoresponsive region.

A $25-\mathrm{eV}$ analysis window around the nominal $\mathrm{Cd} 3 \mathrm{~d}$ binding energy (BE) was recorded along a defined pathway, obtained by electronically indexed translation of the sample stage, with and without violet laser illumination. The resulting line scans are shown in Figures $3 a$ and $3 b$, respectively, as false counter-

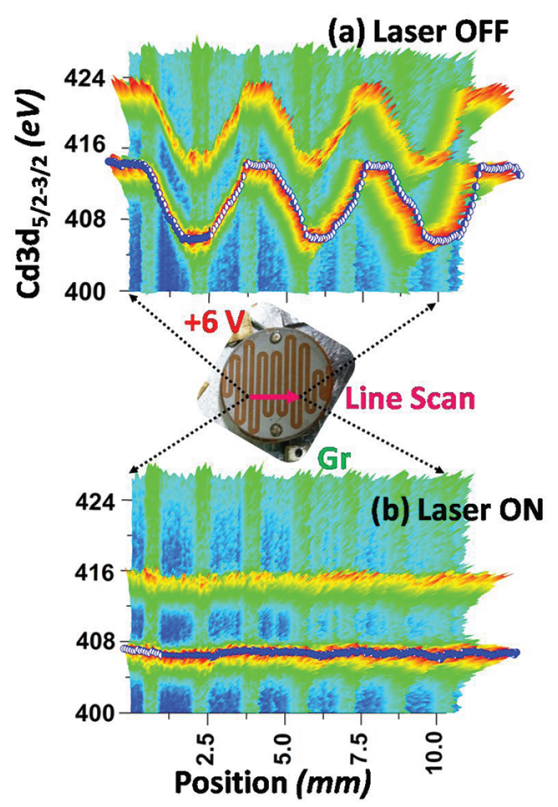

Figure 3. False contour plot of XPS line scan spectra along both the conductive and photoresponsive regions of the device at (a) laser-off and (b) laser-on states. The inset in the middle shows the device and the position of the line scan data recorded.

colored plots. In Figure $4 a$, the measured position of the $3 d_{5 / 2}$ peak is plotted, from which surface potentials were extracted. The close correlation between the surface potential variations and the optical image confirms the consistency of our measurement technique. The applied potential, ranging from $+6 \mathrm{~V}$ to ground, changes only along the photoresponsive region. No detectable variation in the position of the core levels 


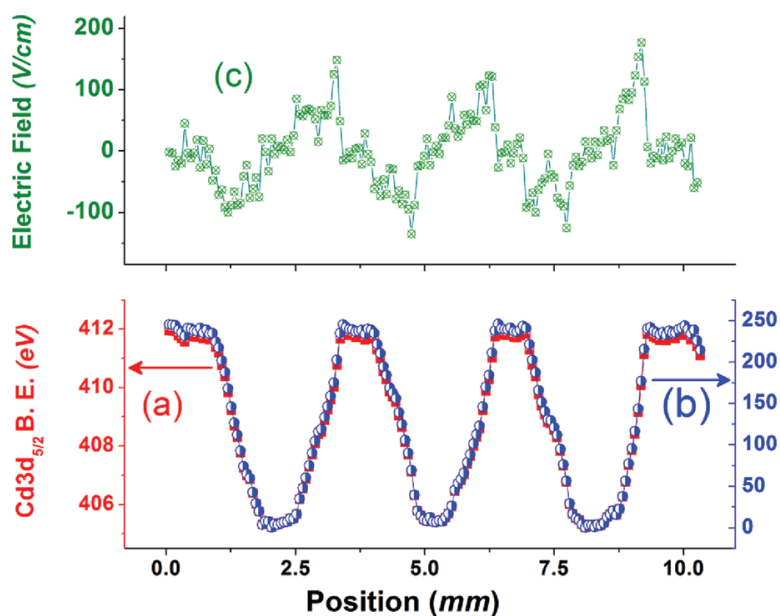

Figure 4. (a) Measured Cd $3 d_{5 / 2}$ binding energy (BE) positions, (b) the corresponding calculated LDR values, (c) and the computed electrical field variations, along the XPS line scan.

was found in the conductive areas. The location-specific surface potential variations can be modeled as

$$
\left[\frac{V_{\text {bias }}}{\left(R_{\text {ext }}+R_{\text {max }}\right)}+I_{\text {xray }}\right] R_{\mathrm{ph}}(x, y)=\Delta V_{\mathrm{XPS}}(x, y)
$$

In this equation, $V_{\text {bias }}$ and $R_{\text {ext }}$ are the magnitudes of the externally applied potential and the ballast resistor, respectively; and $R_{\max }$ is the maximum resistance value of the photoresponsive region. $I_{\mathrm{X} \text {-ray }}$ is a minor current due to the photoelectrons leaving the sample surface, which is constant at $20 \mathrm{nA}$, as measured independently under the experimental conditions used here. The $R_{\mathrm{ph}}(x, y)$ is the unknown locationdependent photoresistance value, and $\Delta V_{\mathrm{XPS}}(x, y)$ is the measured surface potential, obtained by subtraction of the $\mathrm{Cd}$ $3 \mathrm{~d}_{5 / 2}$ peak position, measured at ground potential in darkness, from the measured BEs at any lateral position. The two unknowns are $R_{\mathrm{ph}}(x, y)$ and $R_{\max }$. $R_{\max }$ can be obtained from the boundary conditions. For instance, when the X-ray probe is on an edge of the photoconductive region near the electrode with the maximum positive bias relative to ground, $R_{\mathrm{ph}}(x, y)$ and $R_{\max }$ are equal, from which the value of $R_{\max }$ can be determined. Accordingly, a Matlab program was used to solve the boundary situation to obtain $R_{\max }$. It then uses the equation at each point in a scan to obtain location-specific $R_{\mathrm{ph}}(x, y)$ values, as shown in Figure $4 \mathrm{~b}$. The same procedure provides a map of electric field variations as shown in Figure 4c. Notice that because the electric field is the derivative of the calculated resistance, it is much noisier than the resistance values. The characteristic performance of the LDR under photoillumination with different lasers is shown in Figure 5. The violet and green lasers have energies well above and nearly equal to the band gap of $\mathrm{CdS}(2.4 \mathrm{eV})$, respectively. ${ }^{35}$ Upon illumination, the resistance of the undoped $\mathrm{CdS}$ is diminished to almost zero and only the grounded potential is measured at all locations (the applied voltage is dropped across the ballast resistor). The red laser causes a similar photoresponse, becauase of persistent photoconductivity resulting from absorption of light by defect states in the energy gap of the CdS. The response to the nearinfrared laser is much less as too few of the defects in the energy gap can be ionized at the lower energy of these photons.

XPS maps were recorded across defined areas with equal steps along the horizontal and vertical axes. All of the XPS data

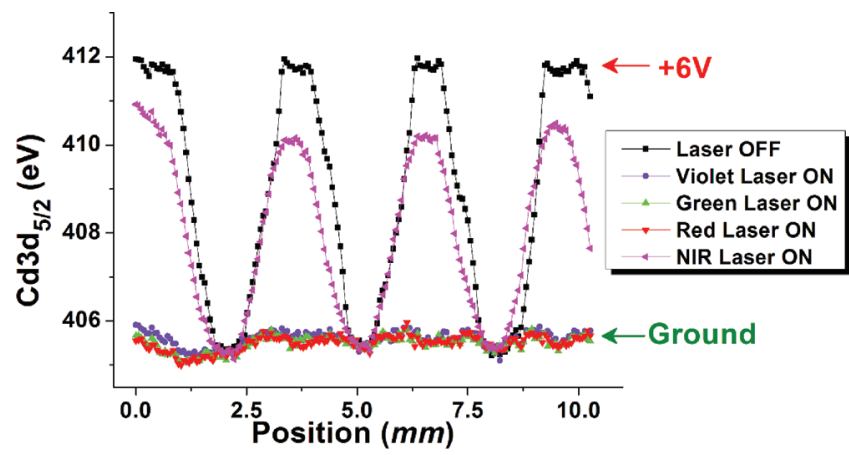

Figure 5. Measured $\mathrm{Cd} 3 \mathrm{~d}_{5 / 2}$ binding energy (BE) positions under four laser illuminations.

was fit with the $\mathrm{Cd} 3 \mathrm{~d}$ envelope to determine the peak positions. A sample map consisting of $10010(130 \times 77)$ individual $\mathrm{Cd} 3 \mathrm{~d}$ spectra (the entire dataset recorded at different binding energies are compiled as a video file in the Supporting Information section) $)^{36}$ is shown in Figure 6. It

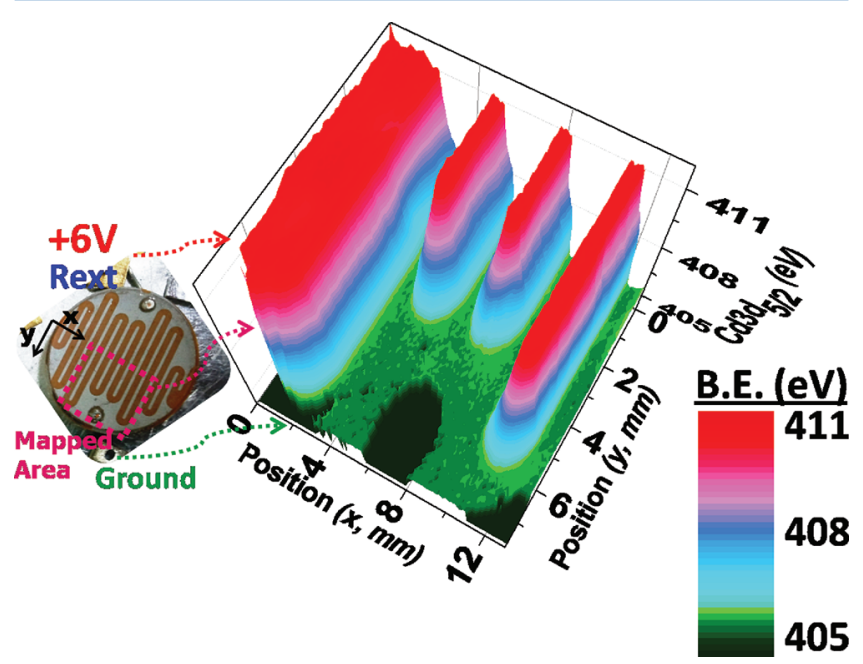

Figure 6. Three-dimensional (3D) aeral map of the $\mathrm{Cd} 3 \mathrm{~d}_{5 / 2} \mathrm{BE}$ position of the region shown in the inset.

exhibits both chemical and electrical contrast between the conductive and photoresponsive regions of the LDR in the absence of illumination. In the false-color contour plot in Figure 6, the "top of the hills" correspond to a $+6 \mathrm{~V}$ biased conductive regions, so the $\mathrm{Cd} 3 \mathrm{~d}_{5 / 2}$ peak is shifted by $6 \mathrm{eV}$, to $\sim 411 \mathrm{eV}$. The "valleys" correspond to the grounded conductive region, shown in green. The high slope represents the photoresponsive regions where the potential is changing rapidly. Similar graphs were generated during the illumination. Examples are shown in Figure 7.

The CdS-based LDR also exhibits defective regions, as shown in detail in Figure 7. At the defect site, the conductive region extends over to the photoresponsive region, so the measured voltage is smaller than expected. However, as shown in Figure $7 \mathrm{c}$, under violet light illumination, the electrical contrast between the defect region and the normal region disappears. Since the near-infrared (NIR) laser causes only a limited photoconductivity, the defect site is more pronounced under NIR illumination. Hence, the technique we describe can provide enhanced defect sensitivity under appropriate conditions. 
(a) Laser OFF

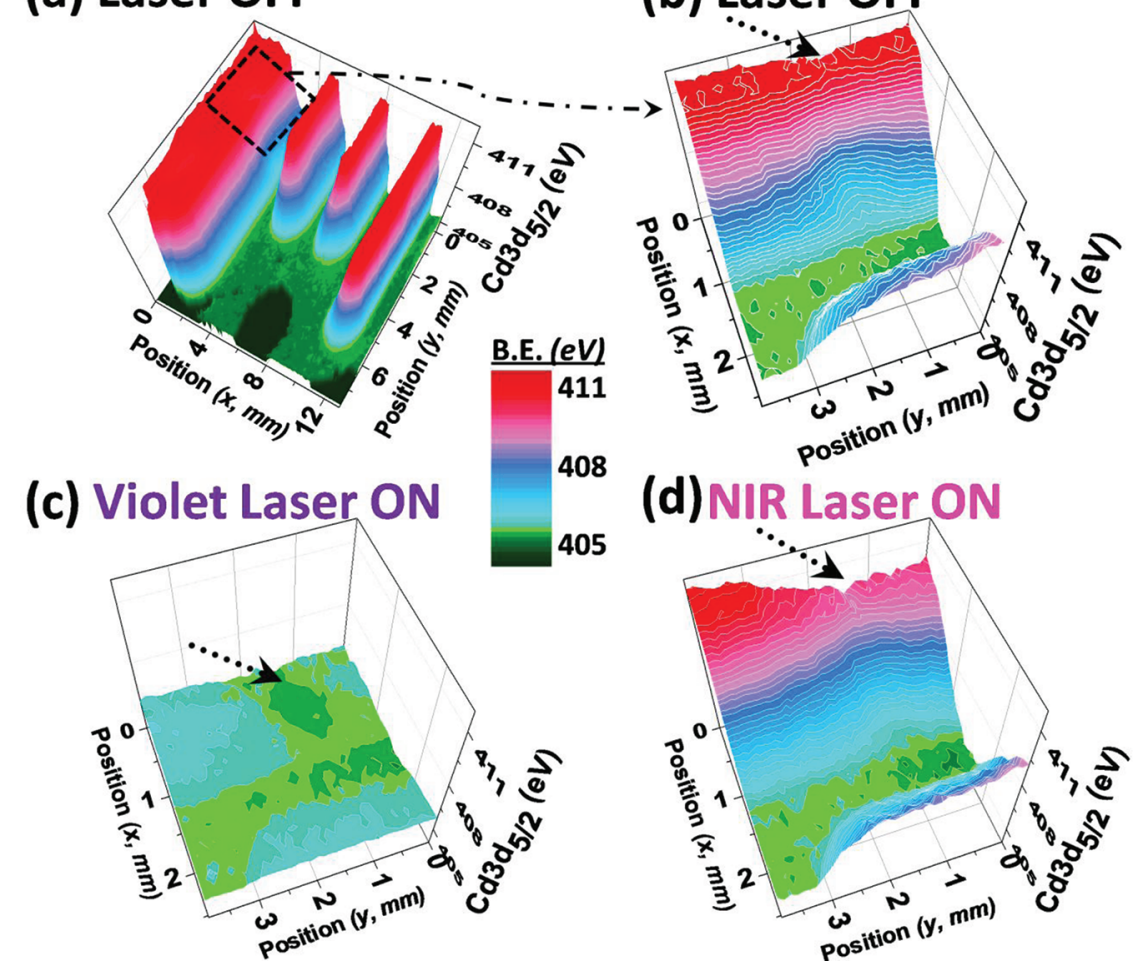

Figure 7. (a) The same 3D aereal map of Figure 6, and the enlarged region of a morphological defect site (indicated by the arrow) under illumination (b) without any laser, (c) with a violet laser, and (d) with a near-infrared (NIR) laser.

\section{CONCLUSIONS}

We have shown that a contactless chemical and electrical measurement of a CdS-based light-dependent resistor (LDR) can be performed under realistic working conditions, using an operando X-ray photoelectron spectroscopy (XPS) technique. The local surface potentials are related to local conductivity; therefore, the experimental setup is modeled by an electrical model to extract electrical parameters with location and chemical specificity from a set of data of XPS line and mapped area scans, without and under photoillumination. The methodology is simple and the derived chemically resolved electrical parameters can be used to assess the performance of devices and/or to detect and identify the nature of defect sites. The potential of the technique demonstrated go significantly beyond what is demonstrated here. For example, by square wave modulation of the exciting laser with different intensities, duty cycles, and frequencies and measurement of the resulting chemical shifts, it will be possible to determine the lifetime of the photoconductivity response and, for normal photoconductive semiconductors, the minority carrier lifetime. ${ }^{37}$ In essence, it will be possible to measure transient photoconductivity in a noncontact, high-resolution mode that will allow a direct connection of reduced carrier lifetimes to specific chemical defects, detectable with XPS.

\section{ASSOCIATED CONTENT}

\section{S Supporting Information}

A video file of the X-ray photoelectron spectroscopy (XPS) data of the CdS-based light-dependent resistor (LDR) under $+6 \mathrm{~V}$ operating conditions. Each frame displays the recorded intensity at the $\mathrm{BE}$ specified as an areal map, and the $\mathrm{BE}$ is stepped by $0.2 \mathrm{eV}$, starting from $400 \mathrm{eV}$ and ending at $425 \mathrm{eV}$. The mapped area is ca. $8 \mathrm{~mm} \times 12.5 \mathrm{~mm}$, as also shown in
Figure 6, and each pixel corresponds to averaged data of 30$\mu \mathrm{m}$-diameter spot size with steps of $60 \mu \mathrm{m}$ between the data points.This material is available free of charge via the Internet at http://pubs.acs.org.

\section{AUTHOR INFORMATION}

\section{Corresponding Author}

*E-mail: suzer@fen.bilkent.edu.tr.

\section{Notes}

The authors declare no competing financial interest.

\section{ACKNOWLEDGMENTS}

This work was partly supported by TUBITAK (The Scientific and Technological Research Council of Turkey), through Grant No. 211 T 029.

\section{REFERENCES}

(1) Gurlo, A.; Riedel, R. Angew. Chem., Int. Ed. 2007, 46, 3826.

(2) Coq, B.; Delahay, G.; Durand, R.; Berthomieu, D.; AyalaVillagomez, E. J. Phys. Chem. B 2004, 108, 11062.

(3) Lee, A. F.; Carr, P.; Wilson, K. J. Phys. Chem. B 2004, 108, 14811.

(4) Guerrero-Pérez, M. O.; Bañares, M. A. J. Phys. Chem. C 2006, $111,1315$.

(5) Whitney, A. V.; Elam, J. W.; Stair, P. C.; Van Duyne, R. P. J. Phys. Chem. C 2007, 111, 16827.

(6) Martínez-Huerta, M. V.; Deo, G.; Fierro, J. L. G.; Bañares, M. A. J. Phys. Chem. C 2008, 112, 11441.

(7) Zhao, C.; Wachs, I. E. J. Phys. Chem. C 2008, 112, 11363.

(8) Klasovsky, F.; Hohmeyer, J.; Brückner, A.; Bonifer, M.; Arras, J.; Steffan, M.; Lucas, M.; Radnik, J.; Roth, C.; Claus, P. J. Phys. Chem. C 2008, 112, 19555.

(9) Rousseau, R.; Schenter, G. K.; Fulton, J. L.; Linehan, J. C.; Engelhard, M. H.; Autrey, T. J. Am. Chem. Soc. 2009, 131, 10516. 
(10) Kimmerle, B.; Grunwaldt, J.-D.; Baiker, A.; Glatzel, P.; Boye, P.; Stephan, S.; Schroer, C. G. J. Phys. Chem. C 2009, 113, 3037.

(11) Melke, J.; Schoekel, A.; Dixon, D.; Cremers, C.; Ramaker, D. E.; Roth, C. J. Phys. Chem. C 2010, 114, 5914.

(12) Gamarra, D.; Fernandez-Garcia, M.; Belver, C.; Martinez-Arias,

A. J. Phys. Chem. C 2010, 114, 18576.

(13) Kendrick, I.; Kumari, D.; Yakaboski, A.; Dimakis, N.; Smotkin, E. S. J. Am. Chem. Soc. 2010, 132, 17611.

(14) Xu, J.; Li, P.; Song, X.; He, C.; Yu, J.; Han, Y.-F. J. Phys. Chem. Lett. 2010, 1, 1648.

(15) Fottinger, K.; van Bokhoven, J. A.; Nachtegaal, M.; Rupprechter, G. J. Phys. Chem. Lett. 2011, 2, 428.

(16) Laoufi, I.; Saint-Lager, M. C.; Lazzari, R.; Jupille, J.; Robach, O.; Garaudée, S.; Cabailh, G.; Dolle, P.; Cruguel, H.; Bailly, A. J. Phys. Chem. C 2011, 115, 4673.

(17) Banares, M. A. Adv. Mater. 2011, 23, 5293.

(18) Phaneuf, R. J.; Kan, H. C.; Marsi, M.; Gregoratti, L.; Gunther, S.; Kiskinova, M. J. Appl. Phys. 2000, 88, 863.

(19) Gregoratti, L.; Mentes, T. O.; Locatelli, A.; Kiskinova, M. J. Electron Spectrosc. Relat. Phenom. 2009, 170, 13.

(20) Barrett, N.; Zagonel, L. F.; Renault, O.; Bailly, A. J. Phys. Condens. Matter 2009, 21, 314015.

(21) Pantel, R. Appl. Phys. Lett. 1983, 43, 650.

(22) Patterson, J. M.; Smith, M. C. 21st Annual Proceedings, Reliability Physics 1983, Phoenix, AZ, April 5-7, 1983; Institute of Electrical and Electronics Engineers (IEEE): New York, 1983; p 150.

(23) Comizzoli, R. B.; Opila, R. L. J. Appl. Phys. 1987, 61, 261.

(24) Opila, R. L.; Marchut, L.; Hollenhorst, J. N. J. Electrochem. Soc. 1990, 137, 703.

(25) Opila, R. L. Appl. Surf. Sci. 2009, 256, 1313.

(26) Giesen, M.; Phaneuf, R. J.; Williams, E. D.; Einstein, T. L.; Ibach, H. Appl. Phys. A 1997, 64, 423.

(27) Ghosal, S.; Hemminger, J. C.; Bluhm, H.; Mun, B. S.; Hebenstreit, E. L. D.; Ketteler, G.; Ogletree, D. F.; Requejo, F. G.; Salmeron, M. Science 2005, 307, 563.

(28) Bluhm, H. J. Electron Spectrosc. Relat. Phenom. 2010, 177, 71.

(29) El Gabaly, F.; Grass, M.; McDaniel, A. H.; Farrow, R. L.; Linne, M. A.; Hussain, Z.; Bluhm, H.; Liu, Z.; McCarty, K. F. Phys. Chem. Chem. Phys. 2010, 12, 12138.

(30) Zhang, C.; Grass, M. E.; McDaniel, A. H.; DeCaluwe, S. C.; El Gabaly, F.; Liu, Z.; McCarty, K. F.; Farrow, R. L.; Linne, M. A.; Hussain, Z. Nat. Mater. 2010, 9, 944.

(31) Pelissier, B.; Beaurain, A.; Barnes, J. P.; Gassilloud, R.; Martin, F.; Joubert, O. Microelectron. Eng. 2008, 85, 1882.

(32) Sezen, H.; Suzer, S. Surf. Sci. 2010, 604, L59.

(33) Sezen, H.; Ozbay, E.; Aktas, O.; Suzer, S. Appl. Phys. Lett. 2011, 98, 111901.

(34) Hill, J. E.; Chamberlin, R. R. U.S. Patent 3,148,084, Sept. 8, 1964.

(35) Amalnerkar, D. P. Mater. Chem. Phys. 1999, 60, 1.

(36) See the Supporting Information section.

(37) Hahn, T.; Schmerler, S.; Hahn, S..; Niklas, J. R. J. Mater. Sci., Mater. Elect. 2008, 19, 79. 